\title{
An efficient business intelligence (BI) model based on green IT and balanced scorecard (BSC)
}

\author{
Abderrazak Bakkas $^{1 *}$ and Abdellah El Manouar ${ }^{2}$ \\ Research Scholar, National Higher School for Computer Science and System (ENSIAS), Mohammed V University, \\ Rabat, Morocco ${ }^{1}$ \\ Professor, National Higher School for Computer Science and System (ENSIAS), Mohammed V University, Rabat, \\ Morocco $^{2}$
}

Received: 02-April-2018; Revised: 16-July-2018; Accepted: 19-July-2018

(C)2018 ACCENTS

\begin{abstract}
Many companies are aware of the need to integrate environmental and social practices into their overall strategy. This paper presents a new business intelligence (BI) model based on green IT and balanced scorecard (BSC). This will enable decision-makers to integrate societal and environmental concerns into the decision-making process as well as monitor the company's environmental performance and their interaction with customers, suppliers and employees. The model gives a new vision for business intelligence not just to focus on the economic aspects, but also to take into account the social, moral and environmental considerations. The aim of this paper is to design efficient BI to introduce and standardize key performance indicators of corporate social responsibility using the four perspectives of the BSC to contribute effectively the green IT. The proposed model gives a new generation model of the BI that is "Green BSC BI".
\end{abstract}

\section{Keywords}

Business intelligence, Green IT, Sustainable development, Corporate social responsibility, Balanced scorecard.

\section{Introduction}

Information and communication technologies (ICT) constitute a major component at the enterprise level and are an inseparable and integral part of modern business. Indeed, ICT is closely linked to the decision-making process. Moreover, it is very difficult to imagine any modern process in a company without information systems (IS). In addition to being an important and necessary support to business processes, IS with information technologies are a creative cause for many new and business interactions. The synergy between the business and the IS follows what business growth implies the growth of IS. This also implies a greater carbon-based carbon generation [1]. ICT now has a new role to play. It helps to create a greener and more sustainable environment while providing economic benefits. Indeed, computers and other ICT infrastructures consume significant amounts of electricity, which increase day by day, placing a heavy burden on our electrical grids and contributing to greenhouse gas (GHG) emissions.

*Author for correspondence

203
In addition, ICT equipment poses ecological problems during its production and recycling [2].

It is true that ICT is considered part of the environmental pollution problem, but it can also be a solution for environmental sustainability. We can harness the power of ICT in innovative ways to address environmental issues and make our IS increasingly green [3, 4]. The green IT is the study and practice of designing, manufacturing and using IT tools (computers, servers, monitors, printers, storage devices and network management systems and communications) with zero or minimal impact on the environment [5, 6]. Green IT encompasses hardware, software, tools, strategy and practice that enhance and stimulate environmental sustainability [2]. Green IT has thus gone beyond the action of buying and using. It is above the way in which the IS are used to reduce the impact on the environment. It is an intelligent use of environmental capital. This approach leads us to talk about the new concept we call "Green balanced scorecard (BSC) BI". The aim is to better exploit the capacity of business intelligence (BI) in the field of environmental sustainability of information technologies. Figure 1 illustrates a synthesis diagram of the problem. 




Figure 1 Synthesis diagram of the problem

The rest of this paper is organized as follows: in the second section a literature review of the three concepts: BI, environmental intelligence and green IT were presented. In the third section the new green BSC BI model with these different axes, and show how this new model based on green IT and environmental intelligence will constitute an alternative to conventional BI by evaluation and application of the model were presented. Finally concluded and deepen with a synthesis of the problem and the research perspectives.

\section{Related work}

The latest work was analyzed in this section based on the BI, green IT and environmental intelligence.

\subsection{Review of literature}

\subsubsection{Business intelligence}

BI provides an overview of the different activities of the company and its environment. In general, the term BI is defined as an umbrella term that includes the applications, infrastructure and tools, and best practices that enable access and analysis of information to improve and optimize decisions and performance [7]. The organization of BI in the company is highly dependent on the organization of the company itself. However, BI can have a structuring impact for the company, notably by formalizing data repositories and setting up a competence center [8].

BI helps administrators by breaking down information from various resources in better basic leadership at both tactical and strategic level, for customary utilization, conventional data frameworks, yet for hierarchical and functional planning [9].

It allows people in an organization to access and analyze data to control the business and improve performance to work efficiently [10]. BI can be seen as a technology that allows users to access not only historical and current data but also to create new correlations. These new correlations between basic data to produce ideas that are used in companies to optimize processes improve customer experience and reduce inventory. BI systems generally include online analysis, reporting, data mining, consolidated dashboard provisioning, and business performance management [1].

It is thus an approach for the processing, enhancement and enrichment of business information in the management context, in order to follow the opportunities offered by the company and anticipate the most crucial risks that may have occurred and, above all, make well-founded and more efficient economic decisions.

BI is helping to improve the quality of strategic planning and to reduce the time spent on decision making by improving and accelerating the decisionmaking process of a company [11]. It is a managerial concept or a tool that is used to control and enrich business information and to produce up-to-date 
knowledge and intelligence for effective and strategic decision-making [12].

According to Gilad and Gilad [11] there are five key tasks in BI:

- Gathering raw data

- Assess the validity and reliability of data and information

- Analyzing data and information

- Store information

- Share information with decision-makers

According to most researchers and practitioners, identify three types of BI have been identified: (1) Strategic BI, (2) Tactical BI and (3) Operational BI. The real difference between these three types of BI application is related to the granularity of the data being analyzed and the frequency, at which it is being captured, analyzed and reported [13]:

- Strategic BI: Used by top management and financial analysts who are interested in analyzing the company's performance in areas with a key role in reaching the strategic objectives.

- Tactical BI: Focuses on reaching the tactical objectives defined for the strategic goals.

- Operational BI: Used to manage and optimize daily business operational transactions

Even if BI helps managers by analyzing data from different resources in better decision making at both strategic and tactical levels, little research available on exploiting the benefits of BI in sustainable development. The presented models do not take into account the sustainability aspect (CSR and Green IT) in the BI approach.

2.1.2Environmental intelligence

Over the last years, the interest in the concept of corporate social responsibility (CSR) has grown, both from a theoretical point of view, to explain this observation, and operational, in the sustained efforts of the different stakeholders in the company to develop long-term performance indicators [14].

The World business council for sustainable development (WBCSD) talks about the business contribution to sustainable economic development, working with employees, their families, the local community and society at large to improve their quality of life.

Indeed, most definitions of CSR describe this concept as the voluntary integration of companies' social and ecological concerns with their business activities and their relationships with their stakeholders. Being socially responsible means not only fully satisfying the applicable legal obligations, but also going beyond and investing "more" in human capital, the environment and stakeholder relations [15].

Today, companies are increasingly conscious about the environmental and social stakes, like the need for protecting an environment in constant degradation and the promotion of safety or health of the workers. The company is not regarded any more solely as one marketing and production equipment having for goal the realization of financial profits, but also entity with the service of societal progress having for mission the realization of the wellbeing of all [16]. The role of the company, thus gradually widened: the mission of the company is not limited only any more to the attack of financial objectives to satisfy its shareholders in the short or medium term, but it includes also today societal concerns which aim at promoting the durability of the company and its longer-term environment. In parallel with this evolution of the company's role in society, the company's performance concept has changed: the traditional vision of the performance which is limited to a financial vision in the short run of the company is gradually replaced by a broader vision, more total and three-dimensional of the performance [17], which includes the achievement of not only the economic objectives of the enterprise but the three categories of sustainable development objectives (economic, social and environmental).

Sustainable development is a development that allows present generations to meet their needs without compromising the ability of future generations to meet their own needs. This is the definition in the report of the World Commission on Environment and Development of the United Nations, known as the Brundtland Report, where this expression first appeared in 1987.

Sustainable development, since the Rio conference, is also represented by the integration of three spheres, according to "three pillars":

- The environment

- The economy

- The social

The three spheres of sustainable development, combining the three objectives of economic efficiency, environmental protection and social equity within a framework of good governance was shown by Marc and Hossam [18]. 
It is in the same logic that Dyllick and Hockerts propose a dominant typology in the field of CSR which comprises three progressive categories of responsible behavior [19], namely:

- Eco-efficiency or economic efficiency: Make efficient use of resources to reduce the environmental footprint.

- Eco-equity: Balance the medium-and long-term needs of society and the company in terms of natural resources.

- Eco-efficiency: Rethinking processes and organizational structures in order to eliminate environmental nuisances.

The interests in a sustainable development approach for a company are as follows [20]:

- Preventing and controlling environmental and social risks

- Meet the requirements of clients and contractors

- Increase overall performance: environmental, social and economic

- Innovation, a competitive advantage and an increase in the value of the brand

- Anticipate or comply with regulatory constraints

- Mobilizing employees to engage in a voluntary and responsible approach

- Meeting expectations and strengthening its relations with its stakeholders: customers, suppliers, employees, shareholders, local authorities, civil society, NGOs, associations, etc.

\subsubsection{Green IT}

Many scientific studies and reports offer the obviousness of the climate change and its potential harmful effects. Specifically, the increasing accumulation of gas with greenhouse effect (GHG) changes the world climate and the weather conditions, the creation of the drought in some countries and floods in others and the increase continues of the total temperature. This poses serious world problems like the drought and other disasters due to the more serious and frequent atmospheric conditions [2]. Moreover, to stop the accumulation of gas with GHG in the atmosphere, of the world emissions should cease increasing and being reduced by $60 \%$ astonishing current levels by 2050 [21].

It is true that ICT are a major component at the enterprise level and are inseparable and integral to modern business, but they also have negative effects on the environment because they consume resources for production, energy in use and generate waste at the end of its life [22]. Indeed, ICT are responsible for $2 \%$ of global carbon emissions, as much as civil aviation (Gartner Group, 2007 [7]). Companies now take into account the environmental impacts of their IS [23], and are increasingly committed to adopting ICT as "Green IT".

The green IT principle began in 1992 when the US environmental protection agency (EPA) launched the "Energy Star", a voluntary labeling approach to identify the energy efficiency characteristics of equipment and to promote products of optimum efficiency in order to reduce greenhouse gas emissions [24].

Green IT is related to the study and practice of designing, manufacturing and using computer tools (computers, servers, monitors, printers, storage devices and network management systems and communications ), with zero or minimal impact on the environment $[5,6]$. Green IT is also about the use of ICT to support, help and increase other environmental initiatives and to help create a "Green" awareness [6]. It encompasses the hardware, software, tools, strategies and practices that enhance and stimulate environmental sustainability [2].

Green IT is a collection of strategic and tactical initiatives that allow [25]:

- Directly reduce the "carbon footprint" of operations related to an organization's information system.

- Use IT services to help reduce an organization's overall "carbon footprint".

- Motivate and support greener behavior by employees, customers and suppliers of an organization.

- Ensure the sustainability of resources used by IT.

According to the contribution of ICTs to the achievement of the objectives of sustainability: ecoefficiency, eco-equity and eco-efficiency [26], typologies of practices of green IT have been distinguished as follows [27]:

- Green IT 1.0: Green for IT: This is the set of methods, software, hardware, services and IT processes that reduce the environmental footprint of ICT through an eco-responsible approach. Namely the saving of energy consumption and waste management. It is like the case of virtualization and dematerialization.

- Green IT 1.5: Organizational optimization, reducing the impact of human organizations (companies, communities, cities, etc.) through communication tools (networks, telephony, etc.). 
This implies a prior dematerialization of the processes. For example the video conferencing.

- Green IT 2.0: IT for Green: the use of ICT to reorganize and optimize products and business processes according to their environmental footprint.

From these three typologies, a distinction can be made between the more or less advanced types of green IT practices; this is the crossing of the sphere of IT or that of the company and the nature of the change of objectives of durability [27].

\section{Materials and methods}

In this section, we detail the new green BSC BI model with these different axes, and show how this new model based on green IT; BSC and environmental intelligence will constitute an alternative to conventional BI, after our model was applied in a use case.

\subsection{Proposal of the new green BSC BI model}

As mentioned in the introduction, ICTs are considered part of the problem of environmental pollution; they now have a new role to play. It helps to create a greener and more sustainable environment while providing the economic benefits of the business. The principle is to exploit the power of ICT in an innovative way in order to face environmental problems and make increasingly green [3, 4] by introducing the concept of sustainable development into the decision-making process (Business Intelligence) as a key element in contributing to green IT. It should also be noted that sustainable development requires decision-making and collaborative tools to guide the organization's approach in this field [28], i.e.:

- Measure and monitor the deployment of the approach.

- Communicate, educate and train employees.

- Integrate, and even anticipate, regulatory developments.

Sustainability measurement relies on key performance indicators (KPIs), relating to the consumption of energy, water and waste, etc. It also requires monetary information on the costs and savings of the environment. This type of information is essential if we want to understand the causal relationships between the different actions that can be taken and their impact on sustainable performance. Hence the idea of exploiting the power of BI in the context of green IT. Moreover, practitioners consider $\mathrm{BI}$ as the result of technologies that are well placed to be used in environmental initiatives of the organization [29].

On the other hand, there is a common trend of organizations adopting new practices such as green IT, but they have not followed up on the success of the implementation of these practices. This type of work usually results in large investments and low consequences for companies. To solve this, they proposed for future research, developing a clearer picture on how to align the company's goals with the implementation of green IT and measure its success. To this end, they proposed the creation of a BSC for the implementation of green IT [30].

Our new model, called "Green BSC BI", will be based on four main axes: green IT, BI, environmental intelligence and BSC. It is to harness the power of BI in green IT based on BSC. This will then expand existing models of green IT. The axes of this new model green BSC BI was presented in the Figure 2.

Based on the four axes of this new model, the main objectives proposed are as follows:

- Sustainability reporting

- Integrated reporting

- Environmental performance management

A new BSC approach to implement the "Green BSC BI" dimensions was proposed. Our approach integrates environmental and societal strategy into the decision-making process. Figure 3 summarizes the components of our new model and the interaction with these different axes.

The expansion and use of BI to progress in the environmental objectives of the organization will benefit both the environment and the company. This is because the combination of BI with environmental factors results in an approach that is not based on the treatment of carbon reduction only as a cost to business. Instead, the approach of environmental intelligence groups BI tools and techniques to achieve business efficiency and environmental [1]. The environmental intelligence collects all resources available to the organization and applied to reduce the organization's carbon emissions without sacrificing its main core objectives. The environmental intelligence also allows an organization to have an overview of its carbon performance and opportunities for improvement in his behavior [1]. 


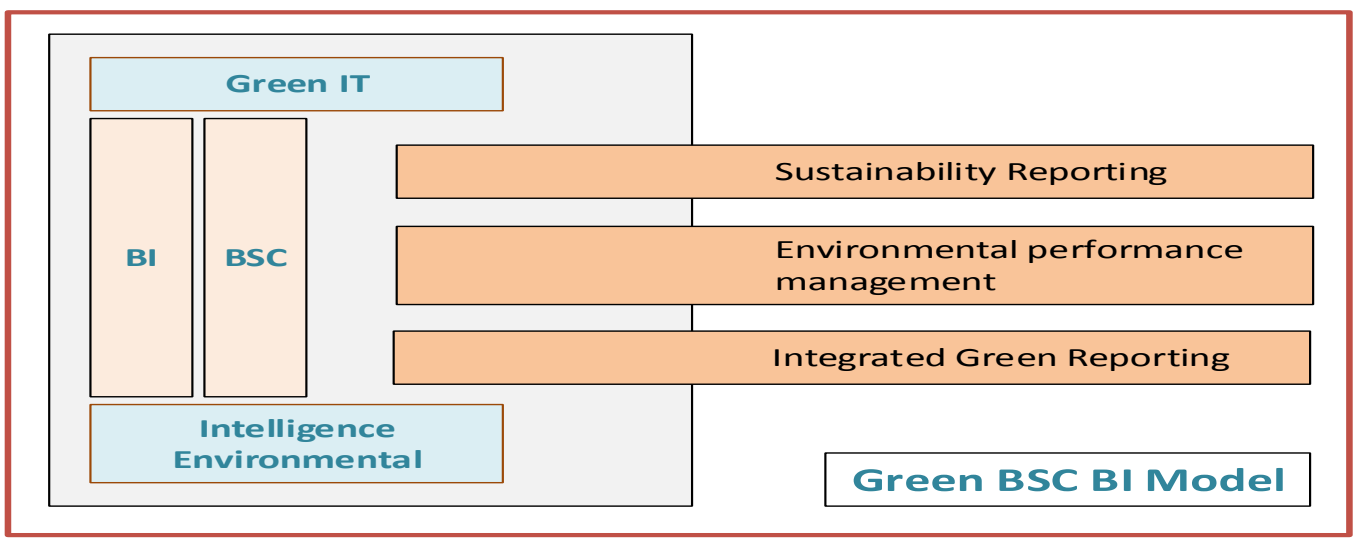

Figure 2 Axes of the new green BSC BI model



Figure 3 The new model "Green BSC BI"

BI is becoming a formidable tool for providing governance information to all stakeholders by incorporating the company's own indicators as well as those of suppliers, investors and customers. In addition to the BI part, our model takes into account the environmental and societal issues of green IT for a wider set. It will also integrate or balance economic, social and environmental considerations within the same performance model.

3.2Evaluation and application of the model

The theoretical "Green BSC BI" model proposed in this work has allowed us to provide a useful framework for examining the potential of implementing green IT and environmental initiatives for BI management. The proposed model is the first attempt to synthesize a theoretical foundation that helps companies to assess their potential for green IT initiatives through BI processes.
This paragraph represents a case study of an agricultural company falling within the set of CSR indicators defined in the strategy of the general management, to monitor and measure corporate social responsibility and sustainability. First, the indicators identified was presented in our case study (Table 1) and the limits of the current state, then the objectives of the implementation was described of the new model to address the limitations encountered. At the end the different categories of indicators based on the new model was proposed (Table 2).

Based on the analysis of the current situation and these indicators, the following limitations were identified:

- Limited to social and environmental aspects

- Does not envisage the correlations between the social aspect and green IT

- Does not address ethics and governance 
- Does not specify how these indicators are selected? Which ones are the most important?

- Does not discuss ethics

- Does not explain how defined indicators will be integrated into the existing management system?

Our goal with the application of our new model is to exceed these limits encountered and to benefit from other advantages, namely:

- Have a procedural method

- Standardization the indicators of corporate social responsibility and sustainability
- Construct the green BSC BI around the four perspectives: finance, stakeholders, future orientation and processes

- Integrates green IT measures within the four perspectives of the scorecard

- Integrate into the core management system.

- Simplicity of design and easy to replicate

After the application of our new model, the selected category of indicators was summarized in Table 2.

Table 1 Indicators corporate social responsibility and sustainability in our case study

\begin{tabular}{ll}
\hline Indicators & Definition \\
\hline Energy consumption & Index to measure consumption of : \\
& Generator \\
& Boiler \\
& Agricultural rolling stock \\
& Pumps \\
& Electricity \\
& Fuel oil \\
& Diesel fuel \\
\hline Irrigation water consumption & Index to measure water consumption \\
\hline Compost consumption & Index to measure consumption of compost \\
\hline Fertilizer consumption & A measure of fertilizer consumption \\
\hline Consumption of phytosanitary products & Index of phytosanitary products consumption \\
\hline Organic production & A measure of organic production \\
\hline Releases & A measure of : \\
& Plastic mulching \\
& Empty packaging \\
& Obsolete stocks \\
\hline Social actions & Cards \\
\hline Renewable energy & Used oils \\
\hline & Tires \\
\hline & Index of social actions \\
\hline
\end{tabular}

Table 2 Case study: application of the new model

\begin{tabular}{ll}
\hline BSC's dimensions & Category of indicators \\
\hline Customer perspective & Improve company's environmental image \\
& Manage social pressures \\
& Customer satisfaction \\
\hline Financial perspective & Reduce energy costs \\
& Reduce operational costs \\
\hline Internal processes perspective & Improve IT asset lifecycle \\
& Reduce data center environmental impact \\
& Reduce energy consumption \\
& Reduce resource consumption \\
& Processes with suppliers and the third parties in general \\
\hline Employee learning \& growth perspective & Improve employee awareness of green IT \\
& Implement environmental management standards \\
& Make IT sustainable \\
& Training and evolution \\
\hline
\end{tabular}




\subsection{Results}

The objective of our model is that the company's performance is not considered just on economic results, arguing that the valuation should include nonfinancial indicators, considering relationships with employees, customers and other stakeholders. The new indicators measure the company's performance in the context of its sustainability and responsibility. Measuring business sustainability involves measuring the extent to which businesses integrate economic, environmental, social and governance factors into their business and the impact of their activities on their environment.

\section{Conclusion and future work}

This paper describes the new green BSC BI model that combines green IT, BI and BSC to better harness the power of ICT in the field of green IT based on the BSC concept. This can help in answering the following main questions:

- How can the impact of ICT be reduced on the environment?

- How can these technologies, on the other hand, contribute to sustainable development?

- Could ICT allow other sectors to reduce their impacts while controlling those associated with their own growth? Should ICTs carry a double responsibility?

- What are the KPIs to be followed?

- Who are the stakeholders in the green IT process?

The term green IT has been used to describe a process of continuous improvement aimed at reducing the environmental, economic and social impact of ICT.

Our work in this paper presents the current situation of the components of the Green BSC BI model. This provides a basis for defining measurement and reporting frameworks, establishing KPIs and baseline measures, and creating a monitoring program to drive continuous improvement of green IT.

This contribution constitutes a first phase of a research work for the development of a new model of BI of new generation based on green IT.

Sustainable development has become a key part of organizational policy and corporate social responsibility, enabling the principles of a more sustainable world to be embodied in a process of continuous improvement.

Future suggestions based on this work are as follows:
- Research is needed in the direction of the limitations of existing BI tools that are used for sustainability issues.

- Work is needed in the direction of integration of proposed green BSC BI model with existing BSC of the organizations.

- Research in the direction of KPIs of the new green BSC BI model is needed.

\section{Acknowledgment}

None.

\section{Conflicts of interest}

The authors have no conflicts of interest to declare.

\section{References}

[1] Unhelkar B. Green IT strategies and applications: using environmental intelligence. CRC Press; 2016.

[2] Murugesan S, Gangadharan GR. Harnessing green IT: principles and practices. John Wiley \& Sons; 2012.

[3] Aronson JS. Making it a positive force in environmental change. IT Professional. 2008; 10(1):43-5.

[4] Ruth S. Green IT. IEEE Internet Computing. 2009; 13(4):74-8.

[5] Murugesan S. Going green with IT: your responsibility toward environmental sustainability. Cutter Consortium; 2007.

[6] Murugesan S. Harnessing green IT: principles and practices. IT Professional. 2008; 10(1):24-33.

[7] Gartner, Business Intelligence. https://www.gartner. com/it-glossary/business-intelligence-bi/. Accessed 30 April 2018.

[8] https://www.cigref.fr/cigref_publications/RapportsCon tainer/Parus2009/Business_Intelligence_CIGREF_200 9.pdf. Accessed 25 March 2018.

[9] https://www.civilica.com/PdfExport-AMCONF01_ 073=A-Model-for-Measuring-the-Direct-and-IndirectImpact-of-Business-Intelligence-on-OrganizationalAgility-with-Partial-Mediatory-role-of-EmpowermentCase-Study-Tehran.pdf. Accessed 30 March 2018.

[10] Howson C. Successful business intelligence. Tata McGraw-Hill Education; 2007.

[11] Gilad T, Gilad B. SMR forum: business intelligencethe quiet revolution. Sloan Management Review. 1986; 27(4):53-61.

[12] Gbosbal S, Kim SK. Building effective intelligence systems for competitive advantage. Sloan Management Review. 1986; 28(1):49-58.

[13] Ahmad A, Razak RA, Osman WR, Rahmat AR, Abdullah MS, Ali AB. Business intelligence model for sustainability of the Malaysian rural telecenters. Journal of Southeast Asian Research. 2011; 2011(2011):1-12.

[14] Tchankam JP, Estay C. The practice of social responsibility and its implications in the company. Management 2000. 2004; 21(4).

[15] https://www.senat.fr/ue/pac/E1776.html. Accessed 30 March 2018. 
[16] Zéghal D, Dammak S. Disclosure of information environmental in reports annuals: a comparative study of American multinationals and European. In accounting and environment 2007(pp.1-18).

[17] Reynaud E. Sustainable development and business: towards a symbiotic relationship. AIMS Day, Sustainable Development Workshop, ESSCA Angers. 2003; 15:1-15.

[18] Rosen MA, Kishawy HA. Sustainable manufacturing and design: concepts, practices and needs. Sustainability. 2012; 4(2):154-74.

[19] Dyllick T, Hockerts K. Beyond the business case for corporate sustainability. Business Strategy and the Environment. 2002; 11(2):130-41.

[20] http://www.solutionsdd.mondeproprete.com/presentation/developpement-durable. Accessed 30 April 2018.

[21] Lash J, Wellington F. Competitive advantage on a warming planet. 2007

[22] DesAutels P, Berthon P. The PC (polluting computer): forever a tragedy of the commons?. The Journal of Strategic Information Systems. 2011; 20(1):113-22.

[23] Kuo B, Dick G. The greening of organisational IT: what makes a difference?. Australasian Journal of Information Systems. 2010; 16(2):81-92.

[24] https://www.energy.gov/eere/solarpoweringamerica/us -environmental-protection-agency. Accessed 30 April 2018.

[25] Hird G. Green IT in Practice: How one company is approaching the greening of its IT. IT Governance Publishing; 2010.

[26] Chen AJ, Boudreau MC, Watson RT. Information systems and ecological sustainability. Journal of Systems and Information Technology. 2008; 10(3):186-201.

[27] Berkhout F, Hertin J. Impacts of information and communication technologies on environmental sustainability: speculations and evidence. Report to the OECD, Brighton. 2001.
[28] https://www.cigref.fr/cigref_publications/RapportsCon tainer/Parus2010/Du_Green_IT_aux_SI_ecoresponsables 2010_CIGREF.pdf Accessed 30 April 2018.

[29] Unhelkar B, Tiwary A. Extending and applying business intelligence and customer strategies for green ICT. In handbook of research on green ICT: technology, business and social perspectives 2011 (pp. 83-97). IGI Global.

[30] https://www.diva-portal.org/smash/get/diva2:536114/ FULLTEXT01.pdf. Accessed 30 April 2018.



Abderrazak Bakkas is a $\mathrm{PhD}$ scholar at the National Higher School for Computer Science and System (ENSIAS), Mohammed V University in Rabat, Morocco. The goal of his research is the reflection on Green IT business intelligence models. He got a National Computer Engineer diploma in 2005, from the ENSIAS Engineering School. He works as an IT manager. He also states the appropriate IT Governance, manages IT Risks, Business Intelligence, Corporate Performance Management, and Organizational Strategy.

Email: ab.bakkas@gmail.com

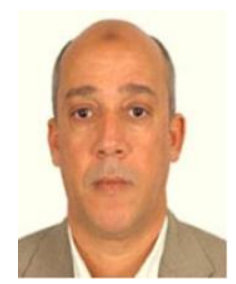

Abdellah El Manouar holds a PhD in economics from Montreal University in 1991, Canada. He is Professor of Higher Education and Head of Business Intelligence Option and IT department and Decision Support. He is member of TIME research team at ENSIAS Engineering School (National Higher School for Computer Science and System), Mohammed V University in Rabat, Morocco. His research topics cover Finance and Investment, Management and New Economy, Financial Management and Financial Engineering.

Email: a.elmanouar@um5s.net.ma 